\title{
Reimagining or revisioning? How one library studied information services
}

n 2010, the Public Services Division of

Northwestern University Library (NUL) launched a reorganization. After a year of study, collaborative work, and planning, a new divisional administrative structure was put into place. A four-department model, organized along functional lines, replaced a sixdepartment structure organized by location. This administrative restructuring was only the beginning of a complete revisioning of services. The next steps_-mapping space and services to the divisional and departmental functions-began while the ink was drying on the new administrative model.

An eight-member Information Services Task Force (ISTF) was formed to review the division's service delivery model and make recommendations for the future. ${ }^{1}$ The work was divided into three areas: study and evaluation of current reference and information service provision, review of service provision from peer institutions, and a literature review. This article outlines the methods, results, and recommendations of this task force; points out the benefits and drawbacks of the group's approach; and indicates some of the next steps in implementing the ISTF recommendations.

\section{Literature review}

ISTF began its study by turning to colleagues for advice and, accordingly, scanned library literature for relevant articles. While group members gathered many good ideas, exact parallels to NUL's situation were not found.
The best guide came from the timely publication of ARL SPEC Kit 327, Reconfiguring Service Delivery, which was published in Spring 2011. ${ }^{2}$

This SPEC Kit addressed some of the very issues that, based on anecdotal evidence, ISTF identified as key to service revisioning. SPEC Kit questions that group members were particularly keen to borrow included queries about consolidation of service points, staffing of desks, and the blending of formerly separate departments and services into one, holistic area. By reviewing the literature, ISTF affirmed its notion, again received anecdotally, that because NUL patrons were looking at information services in an entirely new light, the library's service model needed to be overhauled accordingly.

\section{Philosophy of service}

ISTF members developed six principles of service:

1. We strive to make ourselves visible and available, within the constraints imposed by our building.

2. We serve our public with courtesy and work with our patrons to determine their information needs.

Harriet Lightman is head of research and information services, e-mail: h-lightman@northwestern.edu, and Qiana Johnson is distance learning librarian, e-mail: q-johnson@northwestern.edu, at Northwestern University

(0) 2014 Harriet Lightman and Qiana Johnson 
3. We lead our patrons to what will best serve their needs, according to circumstances and to the best of our ability.

4. We are respectful of different methods of communication.

5. We guide and coach our public and, in so doing, teach them about information resources and delivery.

6. We make our patrons aware of our services in a way that is convenient and effective for them.

These principles became the basis for the philosophy of service that guided the group's

$\mathrm{W}$ O $\mathrm{r}$ k

throughout the nine months that ISTF was operative. ${ }^{3}$ Modeled on the Public Services Division's mission, which was in turn based on the library's strategic plan, the

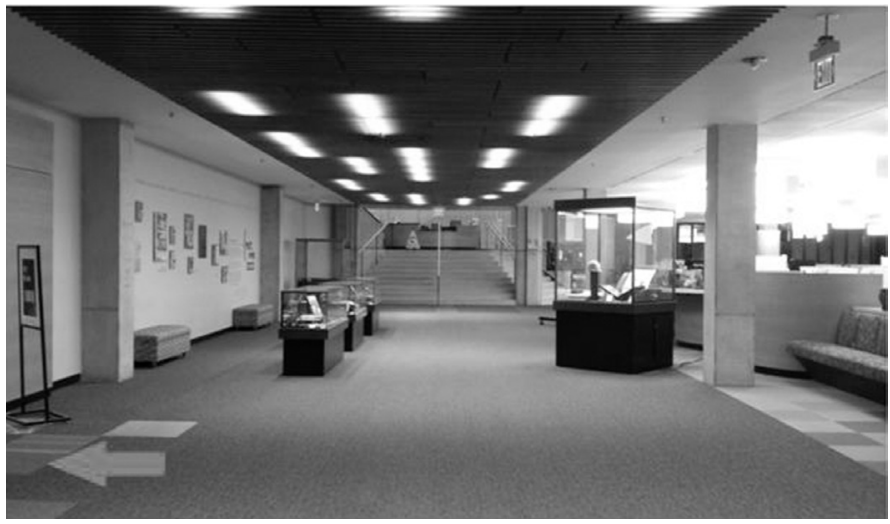

Entrance and main hallway of the Main Library. Arrow notes entrance to old Reference Room. Credit: Sue Oldenburg supported by evidence gathered during the study: the physical layout of the main library building which, although an architectural gem, is difficult to navigate; and the fact that the main reference desk was not in plain sight of patrons when they enter the library (see images). Overcoming these two obstacles proved key to ISTF's recommendations.

\section{External and internal surveys}

Once the literature was reviewed, and the group began to define the outlines of the philosophy of service, ISTF agreed that hard data philosophy was predicated on the strong belief that provision of excellent service is a responsibility that is shared among all members of the Public Services Division. ISTF wrestled with glib phrases: "get them what they want," "get them what they need," "be visible," but underlying that semantic struggle was the assumption that NUL's Public Services staff is committed to providing outstanding service to the immediate university community, as well as to members of the research public. The philosophy of service evolved in the course of ISTF's work, as what began as core beliefs solidified into a firm philosophy, backed up by data and other, more qualitative, evidence.

As ISTF developed a foundational philosophy, group members were mindful of some tangible obstacles to service provision. Two major constraints were identified by ISTF, and was needed to back up the suspicion that the current service configuration was not properly serving NUL's constituencies. Two surveysone of peer institutions (the external study) and one of the internal communityformed the core of the group's evidence, and, subsequently, the basis of the final recommendations.

External survey. ISTF was interested in any recent changes peer institutions had made to their information services, and in using such information in conjunction with internal surveys and some of the SPEC Kit details to develop and implement services appropriate to NUL's specific user community.

ISTF began this process by agreeing to define peer loosely, as institutions similar to (or with close ties to) Northwestern University, and so it was logical to turn to the major consortia to which NUL belongs. These included CARLI (Consortium of Academic and Research Libraries in Illinois), CIC (Committee on Institutional Cooperation), and ARL (Association of Research Libraries). 
Because of significant differences among the schools in these consortia, for two of the consortia ISTF members agreed to identify as peer schools that fit three criteria: private institutions with similar levels of library support, library investment index levels, and total staff size. The exception was CIC. Surveys were sent to all CIC schools because of NUL's close working relationship with members of this consortium.

ISTF members also looked at schools which had some characteristics that matched Northwestern University: libraries at institutions on the quarter system, libraries in large metropolitan areas with a number of other academic libraries, and institutions that had nonsubject specific branches on another cam- Previous entrance to the Reference Room. Credit: Mary Bradley pus. ${ }^{4}$ Because

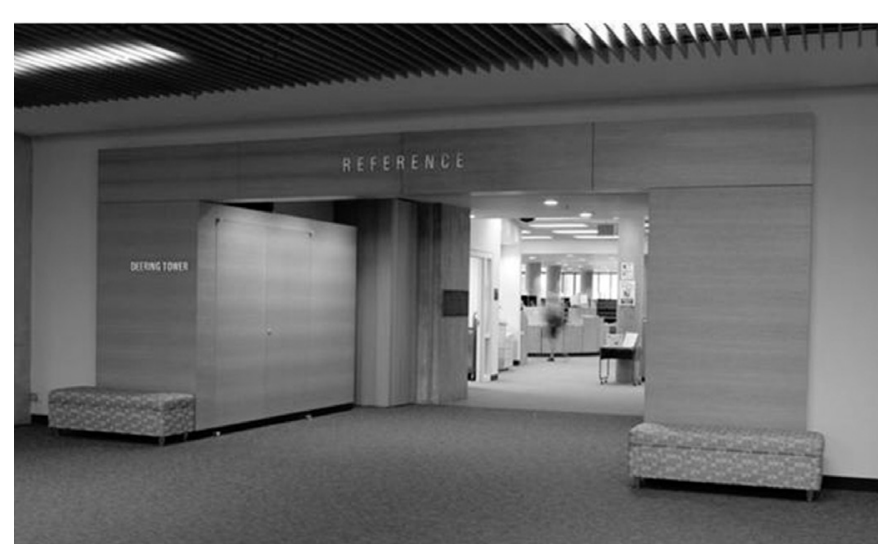
opinion about the location of service points within the library, the staffing levels and hours of service provision of those service points, the effectiveness and frequency of referrals between service points, and staff training.

Four common themes emerged from the responses to these questions: the need for increased training, better signage, the firm belief that public service desks should be in high traffic areas, and the need for the creation of a directory of services, which would be made available at each desk.

The next phase of the internal survey was a study of reference question traffic patterns at each of the 11 desks in the Public Services Division. This study was done during three different time periods in spring quarter 2012. Each service a survey for the SPEC Kit had been done so recently, ISTF's introductory letter to the peers was tailored, acknowledging those schools that had participated in the SPEC Kit and inviting them to expand on the information they provided in that survey.

For those libraries that did not participate in the SPEC survey, the introductory letter asked them to discuss how, if at all, being on the quarter system or having a nonsubject specific branch library affected their information services.

Internal survey. ISTF also gathered information from those members of the NUL staff who work at public service points. A 27-question survey was sent out to all NUL staff, regardless of their home division (at the time of the internal survey, NUL had four administrative divisions). ${ }^{5}$ The survey asked staff who worked at any service desk for their desk was supplied with forms that staff were asked to complete. The forms asked for a description of the content of each question posed at the desk by a patron: if the question had been answered at that desk, if it had been referred to another desk, or if it had been referred to one of the library's subject specialists.

\section{Recommendations}

In developing its final recommendations, ISTF was mindful of the need for change, but equally aware that the most effective services would be ones that were tailored to NUL's specific community and blended new, innovative approaches with the best of traditional public service.

ISTF's chief recommendation, and the one upon which all of the others were based, proposed merging three public services desks that were located on the main floor of 
the library-general reference, government information, and the information commons desk - into one service point, then relocating that point to a high-traffic, high-visibility area of the first floor of the library.

The group next suggested a change to the way in which in-person, on-demand research assistance is provided in the main library. Group members had long observed-and this insight was supported by the internal surveys - that the staffing mix of the general reference desk could be adjusted so that it is staffed by a mix of paraprofessionals, students, and librarians. Under this model, the paraprofessionals and students would be available during the daytime, evening, and weekend hours for quick look-ups and directional questions, while the librarian would be in a consultation area, and on call for in-depth or thorny questions, during the day and select evening and weekend hours.

Building upon the notion that service provision is a shared responsibility that is provided to all members of the NUL community independent of physical place, ISTF recommended changing the staffing models at NUL's two branch libraries-Schaffner Library on the Chicago campus and the Seeley G. Mudd Library on the Evanston campus.

Key to the success of these recommendations, ISTF members believed, was an overhaul of the referral process. The internal surveys suggested that the process by which questions are referred to appropriate subject specialists is, at its best, wobbly. In a group of three interlocking recommendations, ISTF proposed the creation of a subject specialist's portal, the streamlining of telephone and IM/chat services, and the development and implementation of a robust training program for all desk workers and for the subject specialists, not all of whom are in the Public Services Division.

And, of course, the corollary to these three recommendations was a suggestion to better advertise services and to develop and implement an assessment plan. Suggestions for standard signage and a reconfiguration of the reference room rounded out the recommendations.

\section{Implementation and next steps}

ISTF proposed a bold timeline for development and implementation of the new services and service model. Throughout late spring and summer quarters 2013, Public Services Division staff worked together to design and implement ways to move the recommendations forward. ISTF's chief recommendations - the consolidation of three service points into one and the relocation of the reference desk-are well underway. The government information desk was merged with the main reference desk at the end of spring quarter 2013, and a cartographic center, which was launched in late fall quarter 2013, was situated in the area where the government information desk had been (starting this center was part of the recommendation to consolidate service points).

A major renovation of the first floor spaces took place over the summer, and subsequently the reference desk was relocated to a highly visible area. Throughout the summer, public services staff developed new signage, worked to streamline telephone reference, and piloted new ways of providing IM/chat services. Some of the signage and the streamlined phone service were introduced in the fall, while pilots for the chat services were completed in late summer/early fall.

An assessment plan for reference services was completed in spring quarter, and has been used to adjust service hours and level of staff. A working group, appointed in the summer to determine next steps in implementing the ISTF recommendations, has plans for an ongoing training program, which will start in winter quarter 2014. Planning has also begun for a consolidated reference/information commons service desk.

\section{Conclusion}

Looking toward the future, there will continue to be assessment and modification of ISTF's plans, in accordance with the Public Services Division's mission and in keeping with the needs of NUL's patrons. Guided by

(continues on page 462) 


\section{Enabling programs and services}

Goal Area: Operations-Strategic goal areas will be supported by financial and operational planning, and will guide the development and implementation of programs and services that target education, advocacy, and member engagement.

- Approved the minutes of the ACRL Board of Directors Meetings I and II held at the 2014 Midwinter Meeting in Philadelphia.

- Approved the FY15 budget as presented:

o Total ACRL revenues of $\$ 4,454,395$

o Total ACRL expenses of $\$ 4,576,550$

Net ACRL revenues of $(\$ 122,155)$

o Total CHOICE revenues of $\$ 3,000,891$

o Total CHOICE expenses of $\$ 3,233,565$

Net CHOICE revenues of $(\$ 232,674)$
- Approved the recommendation to increase dues by $\$ 2$ for regular members and $\$ 1$ for student and retired members according to the $2.9 \%$ increase in the HEPI index as allowed by ACRL bylaws. The FY15 rates will be:
o Personal members: $\$ 60$
o Student members: $\$ 39$
o Retired members: $\$ 39$ n

("Reimaging or revisioning," cont. from page 448)

a bold vision, unity of purpose, and flexibility, Public Services staff continues to work collaboratively to provide the best possible service to the NUL community.

\section{Acknowledgements}

The authors wish to thank the members of the ISTF for their excellent work, which resulted in the final report which is summarized in this article. The authors also wish to thank Marianne Ryan, associate university librarian for public services, for her comments on this article; Mary Bradley and Sue Oldenburg for their photos; and the members of the Northwestern University Library Public Services Division for their support of the work of ISTF.

\section{Notes}

1. Task Force members were Steven Adams, Life Sciences librarian; Scott Garton, head of the Branch and Off-Campus Services Department; Qiana Johnson, distance learning librarian; Jason Kruse, undergraduate services librarian; William McHugh, principal bibliographer, coordinator for General/Interdisciplinary
Studies, and reference collection management librarian; Geoffrey Swindells, head of the User Experience Department; Greta Zimmer, evening/weekend circulation supervisor. Harriet Lightman, head of the Research and Information Services Department, chaired the Task Force.

2. Kay Vyhnanek and Christy Zlatos, SPEC Kit 327: Reconfiguring Service Delivery (Washington, DC: Association of Research Libraries, 2011).

3. A working group, known as the ISTF Working Group, was formed after the original group's work was complete. The Working Group's purpose is to develop implementation plans for the original task force's recommendations.

4. Northwestern's Schaffner Library, located on the Chicago campus, is a nonsubject specific branch library.

5. Service points not in the Public Services Division included those which came under the purview of the Special Libraries Division, as well as the Entry/Exit and Security desks. $\boldsymbol{n}$ 